\title{
Highly versatile polyelectrolyte complexes for improving the enzyme replacement therapy of
}

\section{lysosomal storage disorders}

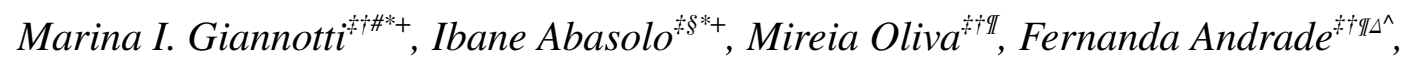
Natalia García-Aranda ${ }^{\sharp s}$, Marta Melgarejo ${ }^{\ddagger ”}$, Daniel Pulido ${ }^{\ddagger ”}$, José L. Corchero ${ }^{\ddagger \neq}$,

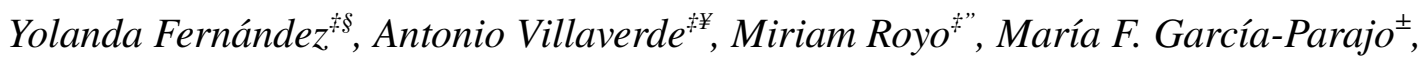
Fausto Sanz $z^{\ddagger \# \#}$, Simó Schwartz Jr ${ }^{\text {\#s }}$.

${ }^{\ddagger}$ Centro de Investigación Biomédica en Red -Bioingeniería, Biomateriales y Nanomedicina (CIBER-BBN), Spain.

${ }^{\dagger}$ Nanoprobes \& Nanoswitches, Institute for Bioengineering of Catalonia (IBEC), Baldiri Reixac 10, 08028 Barcelona, Spain.

\#Physical Chemistry Department, Universitat de Barcelona, 08028 Barcelona, Spain.

${ }^{\S}$ CIBBIM-Nanomedicine. Vall d'Hebron Institut de Recerca (VHIR), Universitat Autònoma de Barcelona, 08035 Barcelona, Spain.

IPharmacy and Pharmaceutical Technology Department, Universitat de Barcelona, 08028 Barcelona, Spain. 
${ }^{\Delta}$ Laboratory of Pharmaceutical Technology, Faculty of Pharmacy, University of Porto, 4050-313 Porto, Portugal.

"Combinatorial Chemistry Unit, Barcelona Science Park, Baldiri Reixac 10, 08028 Barcelona, Spain.

${ }^{\ddagger}$ Institut de Biotecnologia i de Biomedicina and Departament de Genètica i de Microbiologia, Universitat Autònoma de Barcelona, Bellaterra, 08193 Cerdanyola del Vallès, Spain.

${ }^{ \pm}$Institut de Ciencies Fotoniques, The Barcelona Institute of Science and Technology, 08860 Barcelona, Spain \& ICREA, Pg. Lluís Companys 23, 08010 Barcelona, Spain. 


\section{ABSTRACT}

Lysosomal storage disorders are currently treated by enzyme replacement therapy (ERT) through the direct administration of the unprotected recombinant protein to the patients. Herein we present an ionically crosslinked polyelectrolyte complex (PEC) composed of trimethyl chitosan (TMC) and $\alpha$-galactosidase A (GLA), the defective enzyme in Fabry disease, with the capability of directly targeting endothelial cells by incorporating peptide ligands containing the RGD sequence. We assessed the physicochemical properties, cytotoxicity and hemocompatibility of RGD-targeted and un-targeted PECs, the uptake by endothelial cells and the intracellular activity of PECs in cell culture models of Fabry disease. Moreover, we also explored the effect of different freezedrying procedures in the overall activity of the PECs. Our results indicate that the use of integrin-binding RGD moiety within the PEC increases their uptake and the efficacy of the GLA enzyme, while the freeze-drying allows keeping intact the activity of the therapeutic protein. Overall, these results highlight the potential of TMC-based PECs as a highly versatile and feasible drug delivery system for improving the ERT of lysosomal storage disorders.

KEYWORDS: Fabry disease, Enzyme Replacement Therapy, Polyelectrolyte Complexes, Lysosomal Delivery, $\alpha$-galactosidase A, Nanomedicine, Trimethyl chitosan 


\section{INTRODUCTION}

Lysosomal storage disorders (LSDs) comprise a group of rare inherited chronic diseases characterized by the deficiency of specific enzymes at the lysosomal compartment, and the accumulation within these organelles of the macromolecular compounds catabolized by those enzymes. ${ }^{1}$ Although individual LSDs have incidences of less than 1:100,000, as a group the incidence is calculated to be 1 in $7,700 .{ }^{2}$ Nowadays, pharmacological treatment is only available for few of the about 50 known LSDs. In most cases such treatment is based on enzyme replacement therapy (ERT), in which purified recombinant enzyme is infused into the patient. Generally, the efficacy of many ERTs is limited due to the fact that exogenously provided enzymes do not have effect on all clinical aspects of the disease, partly due to the irreversibility of some of them, but also due to enzyme formulations failure to reach all major target organs in therapeutically efficacious doses. ${ }^{3}$ Thus, delivery of therapeutic biomacromolecules to specific cellular types and subcellular compartments is a key objective in drug delivery. In particular, lysosomal targeting and delivery in various specific tissues has become of great interest due to the clinical relevance of enzymes and proteins acting within the lysosome.

Nanoparticle-based drug delivery has been used to improve the activity and delivery of therapeutic macromolecules, like proteins and DNA, providing longer blood circulation times and protecting sensitive biomacromolecules from protease degradation and immune system reactions. ${ }^{4}$ Within the context of protein delivery systems, stimulitriggered release is an appealing and promising approach, especially with the use of 
physiological stimuli like the $\mathrm{pH}$ drop within endo-lysosomal compartments. ${ }^{5,}{ }^{6}$ In addition, addressing clinically relevant end points by targeted delivery has emerged as an approach to maximize the efficiency of a therapeutic macromolecule by strictly localizing its pharmacological activity through controlled biodistribution. ${ }^{7,8}$ Drug delivery to the nucleus or cytoplasm has been extensively explored, ${ }^{9}$ however, lysosomal delivery has only lately turned into the focus of attention. ${ }^{5,10-17}$

The current ERT therapy relies in the natural cellular transit of lysosomal enzymes. As a rule, lysosomal enzymes are produced in the endoplasmic reticulum, glycosylated at the Golgi apparatus, where the mannose-6-phosphate (M6P) is added, and then secreted to the extracellular space. Thereafter, the enzyme is available for the cells to be internalized through $\mathrm{M} 6 \mathrm{P}$ receptors and localized in the lysosomes. This is the mechanism that allows the ERT ${ }^{18}$ and the reason why enzymes administered by ERT have been genetically modified to exhibit an increased glycosylation, allowing better interactions through cell-surface receptors that recognize the carbohydrate moieties. However, alternative enzyme targeting approaches might be necessary to enhance not only the lysosomal destiny of the enzyme but also enzyme accumulation in specific cell types.

$\alpha$-galactosidase A (GLA) is the lysosomal enzyme responsible for the degradation of globotriaosylceramide (Gb3) and other neutral glycosphyngolipids. Its deficiency causes the Fabry disease, resulting in the accumulation of Gb3 in the lysosomes of various cells and tissues, mainly at the vascular endothelium. ${ }^{19-21}$ Therefore, endothelial cells (EC) represent a main target for therapeutical intervention in Fabry disease. Target 
determinants like E-selectin, VCAM-1, ICAM-1 and integrins like $\alpha_{v} \beta_{3}$ and $\alpha_{v} \beta_{5}$ with expression restricted to EC and upregulated during inflammation or angiogenesis, may help to achieve specific and safe delivery of drugs into EC subsets involved in diseases, thereby improving pharmacological efficacy. ${ }^{22,23}$ Peptide ligands containing the arginineglycine-aspartic acid (RGD) sequence display a strong binding affinity and selectivity to integrins, particularly to integrin $\alpha_{v} \beta_{3}$, and have been conjugated to several conventional therapeutic agents for EC targeting and endosomal delivery. ${ }^{24-27}$

Previously, we have described for the first time the development of a $\mathrm{pH}$-responsive nanocarrier for lysosomal delivery of proteins, based on the ionotropic gelation of complexes between trimethyl chitosan (TMC) and the lysosomal enzyme GLA, with triphosphate ions. ${ }^{5}$ With a good protein loading efficiency (around 65\%), these polyelectrolyte complexes (PECs) have appropriate physicochemical properties to remain stable at physiological temperature and $\mathrm{pH}$ (around 7.5), and dissociate and release the protein content at endosomal/lysosomal values ( $\mathrm{pH} 4.5$ to 5.5). We proved that these PECs were efficiently internalized by human cells and mostly accumulated in lysosomal compartments, demonstrating their enormous potential as advanced protein delivery systems for treatment of lysosomal storage diseases. ${ }^{5}$

Following these results, in this work we evaluated the intracellular activity of the PECs, and the possibility to enhance the efficacy of the TMC-based PECs to deliver GLA into the lysosomes of EC by introducing RGD motifs (PEC-RGD). We therefore prepared PEC and PEC-RGD and assessed their physicochemical properties, cytotoxicity and hemocompatibility, as well as cellular uptake by ECs. We further 
investigated the intracellular activity in primary cultures of mouse aortic endothelial cells of GLA deficient mice (MAEC KO cells). In view of optimizing the PEC storage conditions, we also explored the freeze-drying process and the effect on the GLA activity.

\section{EXPERIMENTAL SECTION}

\subsection{Synthesis of N-trimethyl chitosan}

Trimethyl chitosan (TMC) was prepared from chitosan middle-viscous (CS, Fluka) via a two-step procedure, ${ }^{28}$ as reported previously. ${ }^{5}$ Briefly, a mixture of $2 \mathrm{~g}$ of sieved chitosan, $4.8 \mathrm{~g}$ of sodium iodide $(\mathrm{NaI}), 11 \mathrm{~mL}$ of a $15 \%$ aqueous sodium hydroxide $(\mathrm{NaOH})$ solution and $11.5 \mathrm{~mL}$ of methyl iodide $\left(\mathrm{CH}_{3} \mathrm{I}\right)$ in $80 \mathrm{~mL}$ of 1-methyl-2pyrrolidinone was stirred at $60{ }^{\circ} \mathrm{C}$ for $1 \mathrm{~h}$. Special care was taken to keep the methyl iodide in the reaction mixture by using a Liebig condenser. The product was precipitated using ethanol and thereafter isolated by centrifugation. The $N$-trimethyl chitosan iodide obtained after this first step was washed twice with ether on a glass filter to remove the ethanol. It was then dissolved in $80 \mathrm{~mL}$ of 1-methyl-2-pyrrolidinone and heated to $60^{\circ} \mathrm{C}$, thus removing most of the absorbed ether. Subsequently, $4.8 \mathrm{~g}$ of NaI, $11 \mathrm{~mL}$ of $15 \%$ $\mathrm{NaOH}$ solution and $7 \mathrm{~mL}$ of $\mathrm{CH}_{3} \mathrm{I}$ were added with rapid stirring and the mixture was kept at $60{ }^{\circ} \mathrm{C}$ for $30 \mathrm{~min}$. Additional $2 \mathrm{~mL}$ of $\mathrm{CH}_{3} \mathrm{I}$ and $0.6 \mathrm{~g}$ of $\mathrm{NaOH}$ pellets were added and the stirring was continued for $1 \mathrm{~h}$. The product, precipitated with ethanol as described above, was dissolved in $40 \mathrm{~mL}$ of a $10 \%$ sodium chloride $(\mathrm{NaCl})$ aqueous solution to exchange the iodide. The polymer was precipitated with ethanol, isolated by centrifugation and thoroughly washed with ethanol and ether. In vacuum drying yielded 
a white, water-soluble product. Finally, it was dissolved in water and freeze-dried (freeze dryer ALPHA 1-4 LD, Christ). The product was partially quaternized chitosan with $c a$. $50 \%$ of quaternary amines and around $28 \%$ degree of primary amines (free amines), as determined by $1 \mathrm{H}$ NMR. We also observed 22 and $31 \%$ of $O$-methylation for $\mathrm{C}-3$ and C-6, respectively. ${ }^{29}$ The molecular weight of the TMC was estimated to be $202000 \mathrm{~g}$ $\mathrm{mol}^{-1}$ with a polydispersity of 2.6 , via gel permeation chromatography (GPC), using Ultrahydrogel 250 and 500 columns and a Waters 24/4 IR detector, in acetate buffer 0.5 M, pH 3. Dextran standards were employed for calibration. The product had a pKa value of 6.1 and was fully soluble in both water and HEPES buffer at $\mathrm{pH} 7.4$ to 7.5.

\subsection{Fluorescently labeled TMC (TMC-Atto)}

TMC was conjugated to the fluorescent dye Atto 647N NHS ester (Fluka). Atto 647N NHS was first dissolved in dimethyl sulfoxide (DMSO) and then diluted with buffer HEPES $10 \mathrm{mM} \mathrm{pH} \mathrm{7.4.} \mathrm{This} \mathrm{solution} \mathrm{was} \mathrm{added} \mathrm{to} \mathrm{a} \mathrm{TMC} \mathrm{solution} \mathrm{(in} \mathrm{HEPES} 10 \mathrm{mM}$ $\mathrm{pH}$ 7.4) in an approximate molar ratio of $3: 1$, and left to react for $1 \mathrm{~h}$ at room temperature under magnetic stirring. Atto 647N-conjugated TMC was separated from the free dye using Zeba desalt spin columns (Thermo Scientific). In order to increase the amount of conjugated Atto $647 \mathrm{~N}$, a second step was performed and the product was reacted with freshly prepared Atto 647N NHS solution for another hour and, afterwards, separated with Zeba desalt spin columns. The dye-modified TMC (TMC-Atto) solution was freeze-dried (freeze dryer VirTis Freezemobile 25L, SP Scientific, UK). The amount of dye was estimated to be 0.32 moles dye per mol TMC, via UV-visible 
spectrometry (NanoDrop Spectrophotometer ND-1000, Thermo Scientific). TMC-Atto was stored at $-20^{\circ} \mathrm{C}$.

\subsection{RGD-peptide conjugation to TMC (TMC-RGD)}

A RGD cyclic peptide c(RGDfK) derivatized with $N$-succinimidyl $S$-acetylthioacetate (SATA) through the $\varepsilon$-amine of the lysine was obtained following procedures previously described. ${ }^{11,30,31}$ Briefly, the linear peptide was synthesized using standard SPPS on a 2chlorotrityl chloride resin. After cleavage with Acetic Acid/TFE/DCM (1:1:3), peptide was cyclized by treatment of T3P in EtOAc in presence of TEA and DMAP. The final cyclic peptide was deprotected with a mixture of water and TFA (1:19) and purified by semiprep RP-HPLC obtaining peptide c(RGDfK) (180.9 mg, 15\%) as a white solid. To a solution of peptide $\mathrm{c}(\mathrm{RGDfK})(75.9 \mathrm{mg})$ dissolved in $15 \mathrm{~mL}$ of borate buffer $0.02 \mathrm{M}$ at pH 8.2 was added 10 equivalents of SATA $(290 \mathrm{mg})$, the reaction mixture was stirring during 16 h. $^{32}$ After the completion of the reaction, the crude was evaporated and purified by semiprep RP-HLPC, obtaining the final peptide c(RGDfK)-SATA as a solid (13 mg, 14\%).

The obtained peptide was then conjugated to TMC via a $N-[\gamma-$ maleimidobutyryloxy]sulfosuccinimide ester crosslinker (sulfo-GMBS, Pierce). First, c(RGDfk)-SATA was left overnight at room temperature and under stirring in a solution of EDTA $30 \mathrm{mM}$ and $\mathrm{NH}_{2} \mathrm{OH} \cdot \mathrm{HCl} 50 \mathrm{mM}$ to eliminate the acetyl protecting group yielding $\mathrm{c}$ (RGDfk)-sulfhydrylacetamide. In a second step, sulfo-GMBS was added to a TMC solution (10 mg mL $\mathrm{mL}^{-1}$ in buffer HEPES $\left.10 \mathrm{mM} \mathrm{pH} 7.5\right)$ in a concentration of 1 $\mathrm{mM}$ and left to react for $60 \mathrm{~min}$ under stirring at room temperature. Next, the product 
was separated from the non-reacted crosslinker using Zeba desalt spin columns (Thermo Scientific) previously washed 3 times with HEPES buffer solution. This product (TMCcrosslinker) was then incubated with the $\mathrm{c}(\mathrm{RDGfk})$-sulfhydrylacetamide for $1 \mathrm{~h}$ at room temperature and under constant stirring. Finally, the TMC-RGD product was separated from the non-reacted c(RGDfk)-sulfhydrylacetamide using Zeba desalt spin columns, freeze-dried (freeze dryer ALPHA 1-4 LD, Martin Christ Gefriertrocknungsanlagen $\mathrm{GmbH})$ and stored at $-20{ }^{\circ} \mathrm{C}$.

The bicinchoninic acid (BCA) assay (Micro BCA Protein Assay Kit, Thermo Scientific) was used to verify the presence of the RGD peptide in the TMC (TMCRGD), and contrasted with the TMC. Solutions of both polymers (TMC and TMCRGD, as well as a blank of buffer) were incubated at $37{ }^{\circ} \mathrm{C}$ for $2 \mathrm{~h}$ with the BCA assay reagents and, afterwards, the absorbance at $562 \mathrm{~nm}$ was measured.

The BCA assay is regularly used to determine protein concentration in several samples, as the absorbance at $562 \mathrm{~nm}$ of the sample after incubation with the BCA assay reagents (a BCA/copper complex is formed), is linear with increasing protein concentration due to the complex formed (peptide-copper chelates). In the case of peptides smaller than $2000 \mathrm{Da}$, the BCA assay is not suggested for quantization because the absorbance (complex formation) is dependent on the macromolecular structure of the protein, the number of peptide bonds, as well as the presence of cysteine, tryptophan and tyrosine..$^{33}$ Nevertheless, a significant difference in absorbance at $562 \mathrm{~nm}$ for TMC and TMC-RGD treated solutions (light blue and purple, respectively) was detected, corroborating the presence of the RGD peptide in the TMC-RGD samples. In 
consequence, a calibration curve was made by performing the microBCA test on solutions of the free $\mathrm{c}(\mathrm{RGDfk})$ at concentration from 0 to $6 \mu \mathrm{g} \mathrm{mL} \mathrm{m}^{-1}$, in parallel to the samples of TMC and TMC-RGD. A number of 7 RGD moieties per TMC-RGD molecule was estimated.

\subsection{Polyelectrolyte complexes formation}

Recombinant GLA was produced in the HEK $293 \mathrm{~F}$ cell line and purified by affinity chromatography. Briefly, the suspension-adapted human embryonic kidney (HEK) cell line FreeStyle ${ }^{\mathrm{TM}}$ 293-F (Invitrogen ${ }^{\mathrm{TM}}$, Life Technologies, ref. R790-07) was used to produce GLA by polyethylenimine (PEI)-mediated transient gene expression. Details of GLA production and purification have been previously described. ${ }^{34}$

Polyelectrolyte complexes (PECs) between GLA and TMC were prepared by ionotropic gelation with penta-sodium triphosphate (TPP, Fluka). ${ }^{5}$ The PECs were obtained by adding TMC solution (solution A) to GLA (+ TPP) solution (solution B) in a volume ratio 70:30, followed by vortex mixing for $5 \mathrm{~s}$ and $30 \mathrm{~min}$ incubation at room temperature. For neat PECs, solution A: $35 \mu \mathrm{g} \mathrm{mL} \mathrm{m}^{-1}$ of TMC, while for fluorescently labeled PECs (PEC-Atto), solution A: $35 \mu \mathrm{g} \mathrm{mL} \mathrm{m}^{-1}$ of TMC:TMC-Atto (70:30 mass ratio). Solution B was always $70 \mu \mathrm{g} \mathrm{mL}^{-1} \mathrm{GLA}$ and $23 \mu \mathrm{g} \mathrm{mL}^{-1} \mathrm{TPP}$. All solutions were in buffer HEPES $10 \mathrm{mM}, \mathrm{pH}$ 7.4-7.5. The final GLA concentration of the suspension was $21 \mu \mathrm{g} \mathrm{mL} \mathrm{m}^{-1}$.

For RGD decorated PECs (PEC-RGD), first, TMC solution $\left(35 \mu \mathrm{g} \mathrm{mL}^{-1}\right)$ was added to solution B, and mixed for $5 \mathrm{~s}$. Then, TMC-RGD solution $\left(35 \mu \mathrm{g} \mathrm{mL}^{-1}\right)$ was added to the mixture, vortex mixed for $5 \mathrm{~s}$ and $30 \mathrm{~min}$ incubation at room temperature. The mass 
ratio TMC:TMC-RGD was varied between 100:0 and 50:50, and the final volume ratio between TMC solution (TMC+TMC-RGD) and solution B was always 70:30.

Fluorescently labeled PEC-RGD (PEC-Atto-RGD) were obtained as PEC-RGD but replacing TMC solution for (TMC:TMC-Atto solution 70:30 mass ratio). The mass ratio between TMC:TMC-Atto:TMC-RGD was 20:30:50. The final volume ratio between TMC solution (TMC+TMC-Atto+TMC-RGD) and solution B was 70:30.

All PECs were characterized and used as obtained, without further purification or separation steps. When necessary, they were stored at $4{ }^{\circ} \mathrm{C}$.

\subsection{Freeze-drying of PECs}

Prior to freeze drying (FD), the eutectic point of PEC suspensions was determined by means of resistivity measurements, using an Autolab PGSTAT 12 potentiostat (EcoChemie, NL). In all samples tested, the eutectic point was within the temperature range from $-23.3{ }^{\circ} \mathrm{C}$ to $-24.5{ }^{\circ} \mathrm{C}$. Therefore, freezing at $-40{ }^{\circ} \mathrm{C}$ (the standard freezing temperature of the employed freeze-dryer) seemed a reasonable safety limit (without relevant loss of sublimation motive strength), even if lower temperatures were also tested when freezing in liquid nitrogen.

FD vials $(4 \mathrm{~mL})$ were filled with $1 \mathrm{~mL}$ PECs suspension. A LyoMega-30 freeze-dryer (Telstar, Terrassa, Spain) equipped with product temperature probes was used. Moreover, $40 \mu \mathrm{L}$ of a $5 \%$ mannitol solution in HEPES $10 \mathrm{mM}, \mathrm{pH} 7.4$ were added in half of the samples in order to get isoosmotic solutions. The conditions for the different freeze-drying cycles tested are detailed in Table 1. All freeze-dried PECs were stored at $4{ }^{\circ} \mathrm{C}$, and before characterization $1 \mathrm{~mL}$ of ultrapure water was injected inside the vials 
for resuspension. Samples were thereafter identified with the freeze-drying cycle employed (FD1, FD2 or FD3), and an M in case mannitol was introduced.

Table 1. Freeze-drying protocols used with PECs

\section{FD1 FD2 FD3}

\begin{tabular}{lccc}
\hline Chamber T at product entrance $\left({ }^{\circ} \mathrm{C}\right)$ & 25 & -40 & -40 \\
\hline Product T at entrance $\left({ }^{\circ} \mathrm{C}\right)$ & 25 & 4 & -120 \\
\hline Freezing T $\left({ }^{\circ} \mathrm{C}\right)$ & -40 & -40 & -40 \\
\hdashline Sublimation T $\left({ }^{\circ} \mathrm{C}\right)$ & +20 & +20 & +20 \\
\hline Final T $\left({ }^{\circ} \mathrm{C}\right)$ & +30 & +30 & +30 \\
\hdashline Condenser T $\left({ }^{\circ} \mathrm{C}\right)$ & -50 & -50 & -50 \\
\hline Vacuum limit $(\mu \mathrm{mHg})$ & 300 & 300 & 300 \\
\hline Total duration $(\mathrm{h})$ & 30 & 24 & 18
\end{tabular}

\subsection{Dynamic light scattering characterization}

Size and size distribution of PECs was characterized by dynamic light scattering (DLS) based on intensity. The instrument (Zetasizer Nano ZS, Malvern Instruments) was equipped with a He-Ne laser $(\lambda=633 \mathrm{~nm})$ as the incident beam, and folded capillary cells were used. The average size $(D)$, polydispersity index $(P D I)$ and Zeta potential $(\xi-$ potential) values were determined at $25^{\circ} \mathrm{C}$. The $P D I$ describes the width of the particle size distribution, and scale ranges from 0 (monodisperse) to 1. For a single size population following a Gaussian distribution, then the PDI is related to the standard deviation $(\sigma)$ of the distribution in the fashion: $P D I=(\sigma / D)^{2}$.

\subsection{Cell line cultures}


Human microvascular endothelial cell line CDC/EU.HMEC-1 (HMEC-1) cells were provided by Centers for Disease Control and Prevention (CDC-NIDR) and maintained in MCDB 131 supplemented with 50 units $\mathrm{mL}^{-1}$ penicillin, $50 \mu \mathrm{g} \mathrm{mL}^{-1}$ streptomycin, 10 mM L-glutamine and 10\% fetal bovine serum (FBS). HeLa cells, from human cervix carcinoma were obtained from ATTC and maintained in RPMI media supplemented with FBS, antibiotics and $L$-glutamine. Both cell lines were kept in a $37{ }^{\circ} \mathrm{C}$ humidified atmosphere with 5\% $\mathrm{CO}_{2}$. Media, sera and antibiotics were purchased from Invitrogen.

\subsection{Cytotoxicity and hemocompatibility of PECs}

Biocompatibility of PECs was evaluated as previously described. ${ }^{35,}{ }^{36}$ Briefly, cell cytotoxicity was tested using 3-[4,5-dimethylthiazol-2-yl]-2,5-diphenyltetrazolium bromide (MTT) on HeLa and HMEC-1 cells. Cells were exposed to different doses of PECs (PEC or PEC-RGD) during $72 \mathrm{~h}$, and at the end of the incubation period, $5 \mathrm{mg}$ $\mathrm{mL}^{-1}$ of MTT solution was added to the wells. Formazan crystals were dissolved with DMSO and spectrophotometrically measured at $590 \mathrm{~nm}$ (Biotek ELx800 Absorbance Microplate Reader, Izasa Scientific). The data are expressed as the percentages of viable cells compared to the cell survival of a control non-treated group.

For hemocompatibility tests, mouse red blood cells (RBC) were isolated from three wild type C57BL6 mice, resuspended in 2\% (v/v) in PBS and exposed to different concentrations of PECs during $1 \mathrm{~h}$ at $37{ }^{\circ} \mathrm{C}$. The amount of hemoglobin released was measured in a spectrophotometer at $405 \mathrm{~nm}$ (Biotek ELx800) and referred to a positive control of $100 \%$ hemolysis obtained after incubating RBC with $1 \%$ of Triton-X.

\subsection{Cell internalization}


To study the integrin mediated internalization of PECs, HMEC-1 cells were incubated with Atto 647-labeled PECs $\left(12.5 \mu \mathrm{g} \mathrm{mL}^{-1}\right)$ resuspended into MCDB 131 without FBS for 10 or 20 min at $37{ }^{\circ} \mathrm{C}$. Cells were subsequently washed twice with Dulbecco's phosphate buffered saline (DPBS) solution and subjected to fluorescence-activated cell sorting (FACS) analysis. Data acquisition and analysis was performed using FACScan (Beckton-Dickinson) and BD FACSDiva software. A minimum amount of $10^{4}$ viable cells were evaluated in each experiment and the percentage of positive cells as well as mean fluorescence intensity (MFI) were recorded.

\subsection{Specific enzymatic activity}

GLA enzymatic activity was assayed fluorometrically as described by Desnick et al. ${ }^{37}$ with the modifications of Mayes et $a l^{38}$ Basically, it was assayed by using 4Methylumbelliferyl $\alpha$ - $D$-galactopyranoside (4-MUG, Sigma Chemical) as substrate, at a concentration of $2.46 \mathrm{mM}$ in assay buffer (0.01 M acetic acid, $\mathrm{pH} 4.5)$. A typical assay reaction mixture contains $100 \mu \mathrm{L}$ of substrate and $25 \mu \mathrm{L}$ of the sample. Enzymatic reactions took place in agitation (tubes placed in a rotator, set at a rotation speed of 25 $\mathrm{rpm}$ ), at $37{ }^{\circ} \mathrm{C}$ for $1 \mathrm{~h}$, and were stopped with $1.25 \mathrm{~mL}$ of $0.2 \mathrm{M}$ glycine buffer (pH 10.4). The released product, 4-methylumbelliferone (4-MU), was determined by fluorescence measurement at 365 and $450 \mathrm{~nm}$ as excitation and emission wavelengths, respectively. Samples of commercial 4-MU (Sigma Chemical) ranging from 5 to $500 \mathrm{ng}$ $\mathrm{mL}^{-1}$ in $0.2 \mathrm{M}$ glycine buffer $\mathrm{pH} 10.4$, were used to obtain a calibration curve in order to transform fluorescence readings into 4-MU concentration. Specific enzymatic activities are expressed as " $\mu \mathrm{mol}_{4-\mathrm{MU}} \mathrm{mg}_{\mathrm{GLA}}{ }^{-1} \mathrm{~h}^{-1}$ ", or as activity concentrations $(\mathrm{U} / \mathrm{mL})$. 


\subsection{NBD-Gb3 assays in endothelial primary cultures of Fabry mice}

Primary cultures of mouse aortic endothelial cells (MAEC) of GLA deficient mice (GlatmKul1) were isolated at the ICTS 'NANBIOSIS', more specifically the CIBERBBN's In Vivo Experimental Platform at the Functional Validation \& Preclinical Research (FVPR) area (www.nanbiosis.es/unit/u20-in-vivo-experimental-platform), following procedures previously described. ${ }^{11,}{ }^{39}$ Endothelial origin of isolated cells was confirmed by CD105 staining. For activity assays, cells in passages 2 to 5 were seeded in 24 well plates and maintained at $37{ }^{\circ} \mathrm{C}$ and $5 \%$ of $\mathrm{CO}_{2} .24 \mathrm{~h}$ after seeding $8 \mu \mathrm{M}$ of fluorescent $N$-Dodecanoyl-NBD-ceramide trihexoside (NBD-Gb3, Matreya LCC) was added to the cultures along with the specified concentrations of tested compounds (free GLA enzyme, freshly prepared PEC, PEC-RGD, freeze-dried PEC). After $48 \mathrm{~h}$ incubation, cells were trypsinized and NBD-Gb3 fluorescent signal was analyzed by flow cytometry (FacsCalibur, Beckton Dickinson) and FCS Express v4 software. To calculate the percentage of NBD-Gb3 signal, fluorescent signal in control cells (without treatment) was established as $100 \%$ and the values were normalized accordingly. Since GLA activity reduces those Gb3 deposits, the percentage of Gb3 loss (\% Gb3 loss $=100$ -\% Gb3-NBD signal) was used to plot the results. When needed, IC50 values were calculated using GraphPad Prism 5 software.

\subsection{Animal experimentation}

C57B16 wild type animals and Gla ${ }^{\text {tmlKul }}$ GLA deficient mice ${ }^{40}$ were used as source of red blood cells and MAEC, respectively. Animal care was handled in accordance with the Guide for the Care and Use of Laboratory Animals of the Vall d'Hebron University 
Hospital Animal Facility, and following experimental procedures previously approved by the Animal Experimentation Ethical Committee at the institution.

\section{RESULTS}

3.1 Preparation and characterization of RGD-conjugated and fluorescently labeled PECs

The polyelectrolyte complexes (PECs) between GLA and TMC were prepared by ionotropic gelation with penta-sodium triphosphate, as previously reported, ${ }^{5}$ and characterized by DLS. We obtained particles with diameters in the range of 170 to 215 $\mathrm{nm}$ at room temperature, and $\xi$-potential values around $19 \mathrm{mV}$ (Table 2).

To obtain RGD-conjugated-PECs (PEC-RGD), the mass ratio TMC:TMC-RGD was varied between 100:0 and 50:50, and the PECs were prepared and characterized by DLS. We found that the incorporation of TMC-RGD lead to a slight decrease of PECs zeta potential value (19 $\mathrm{mV}$ for PEC and $17 \mathrm{mV}$ for PEC-RGD) with no significant variation of the average diameter when up to $50 \%$ TMC was replaced by TMC-RGD (Table 2). In view of the small change observed for the system, we performed additional studies with the PEC-RGD obtained using a TMC:TMC-RGD mass ratio of 50:50.

In a similar manner, TMC was replaced in part by TMC-Atto to obtain fluorescently labeled PECs (PEC-Atto), or by TMC-RGD and TMC-Atto, to obtain fluorescently labeled RGD-conjugated PECs (PEC-Atto-RGD) (see Experimental section). As shown in Table 2, the introduction of the fluorochrome did not significantly alter the PECs size. The $\xi$-potential of both PEC-Atto and PEC-Atto-RGD was around $16 \mathrm{mV}$, slightly lower than that for PEC. PEC labeled Atto 647N have been characterized by single-molecule 
fluorescence in a previous report, ${ }^{5}$ revealing that they were homogeneous in size and possessed good colloidal stability in water/HEPES and serum free cell culture medium.

Table 2. DLS average diameter D, PDI and $\xi$-potential of PEC, PEC-RGD, PEC-Atto and PEC-Atto-RGD, in $10 \mathrm{mM}$ HEPES buffer $\mathrm{pH} 7.5$, at $25^{\circ} \mathrm{C}$. Depicted results are the average from 3 independent samples.

\begin{tabular}{|c|c|c|c|}
\hline & $\begin{array}{l}\text { Average size } \\
D \\
(\text { Mean } \pm \text { SD })(\mathrm{nm})\end{array}$ & $\begin{array}{l}\text { PDI } \\
(\text { Mean } \pm \text { SD })\end{array}$ & $\begin{array}{l}\xi \text {-potential } \\
(\text { Mean } \pm \text { SD }) \\
(\mathrm{mV})\end{array}$ \\
\hline PEC & $177 \pm 30$ & $0.19 \pm 0.08$ & $18.7 \pm 3.9$ \\
\hline PEC-RGD & $186 \pm 11$ & $0.21 \pm 0.04$ & $17.0 \pm 2.5$ \\
\hline PEC-Atto & $241 \pm 19$ & $0.12 \pm 0.03$ & $16.4 \pm 3.4$ \\
\hline PEC-Atto-RGD & $212 \pm 30$ & $0.13 \pm 0.03$ & $16.7 \pm 2.9$ \\
\hline
\end{tabular}

\subsection{Physico-chemical characterization of freeze-dried PEC}

PEC suspensions were freeze-dried following 3 different freezing protocols (see Experimental section). PECs were characterized within $24 \mathrm{~h}$ after preparation, whereas freeze-dried PECs were characterized immediately after resuspension.

Remarkable differences were observed between different FD cycles (see Table 3). Regarding particle size, a notable reduction in the average diameter was observed when using FD2 cycle, resulting in a compaction of the particles, and the addition of mannitol did not cause any particle size increase. Instead, when freeze-drying following FD1 and 
FD3 cycles, a slight diameter increase was observed, being almost twofold when mannitol was added. On the other hand, higher PDI values were obtained for all particles after freeze-drying, even if these were lower than 0.3 for PEC-FD1, PEC-FD2 and PEC-FD2-M, which are still acceptable PDI values. Besides, minor $\xi$-potential decrease was observed after freeze-drying by cycles FD1 and FD2, whereas an important drop off was achieved after freeze-drying by cycle FD3. However, in general terms, lower $\xi$-potential values are obtained in formulations containing mannitol.

Table 3. DLS average diameter D, PDI and $\xi$-potential of PEC, PEC-FD1, PEC-FD1-M, PEC-FD2, PEC-FD2-M, PEC-FD3 and PEC-FD3-M, in 10 mM HEPES buffer $\mathrm{pH} 7.5$, at $25^{\circ} \mathrm{C}$. Depicted results are the average from 3 different measurements of the same sample.

\begin{tabular}{|c|c|c|c|}
\hline & $\begin{array}{l}\text { Average size } \\
D \\
(\text { Mean } \pm \text { SD }) \\
(\mathrm{nm})\end{array}$ & $\begin{array}{l}P D I \\
(\text { Mean } \pm \text { SD })\end{array}$ & $\begin{array}{l}\xi \text {-potential } \\
(\text { Mean } \pm \text { SD }) \\
(\mathrm{mV})\end{array}$ \\
\hline PEC & $267 \pm 4$ & $0.15 \pm 0.02$ & $18.7 \pm 1.1$ \\
\hline PEC-FD1 & $298 \pm 1$ & $0.28 \pm 0.01$ & $17.4 \pm 3.7$ \\
\hline PEC-FD1-M & $574 \pm 31$ & $0.64 \pm 0.05$ & $16.9 \pm 4.1$ \\
\hline PEC-FD2 & $226 \pm 4$ & $0.25 \pm 0.03$ & $17.5 \pm 1.5$ \\
\hline PEC-FD2-M & $226 \pm 6$ & $0.28 \pm 0.01$ & $17.2 \pm 1.8$ \\
\hline PEC-FD3 & $275 \pm 16$ & $0.37 \pm 0.07$ & $14.4 \pm 2.1$ \\
\hline PEC-FD3-M & $464 \pm 32$ & $0.44 \pm 0.05$ & $11.3 \pm 3.4$ \\
\hline
\end{tabular}




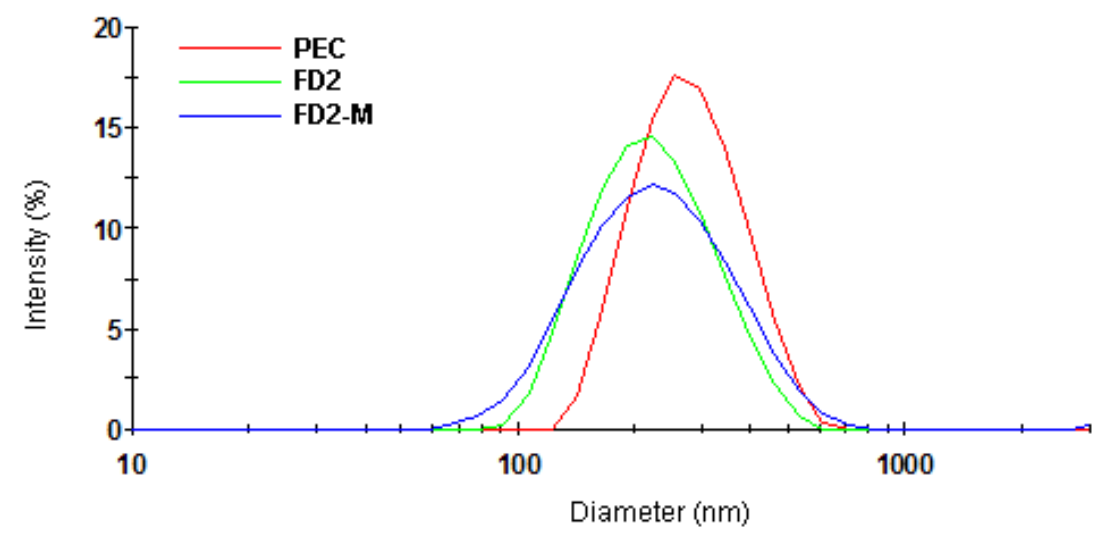

Figure 1. Particle size distribution of freshly prepared PEC, and PEC freeze-dried following the protocol 2, with (PEC-FD2-M) and without (PEC-FD2) mannitol.

\subsection{Cytotoxicity and hemocompatibility}

It has been proposed that strong interaction of cationic nanoparticles with the cell membrane may cause damage by membrane disruption, leading to cell death. ${ }^{41}$ Therefore investigation of the potential cytotoxicity of the PECs is important in order to exclude biological responses due to cell death. Cell viability of PEC and PEC-RGD was evaluated on HeLa (ovarian carcinoma) and on HMEC-1 (microvasculature endothelial cells) cell lines. HeLa is a reference cell line, routinely used in cytotoxicity assays. HMEC-1 is an immortalized human microvascular endothelial cell line that retains the morphologic, phenotypic and functional characteristics of normal human microvascular endothelial cells. ${ }^{42}$ It was chosen because the vascular endothelium represents a target of choice for therapeutic intervention in Fabry disease. Cells were exposed during $72 \mathrm{~h}$ to different doses of PEC or PEC-RGD, up to $5.5 \mu \mathrm{g} \mathrm{mL} \mathrm{m}^{-1}$, and then evaluated using the 
MTT assay. For HeLa and HMEC-1 cells, cell viability slightly decreased up to values around $80 \%$ for the highest concentration tested (Figure 2).

To test the hemocompatibility of PEC and PEC-RGD, the percentage of hemolysis of mouse RBC was assessed for different PEC or PEC-RGD concentrations up to $2.7 \mu \mathrm{g}$ $\mathrm{mL}^{-1}$. Hemolysis for both PEC and PEC-RGD was always lower than $1 \%$ for the tested concentrations (Figure 3). These results indicate that both PEC and PEC-RGD cytotoxicity is very low and they do not induce hemolysis in concentrations below 5.5 $\mu \mathrm{g} \mathrm{mL}^{-1}$
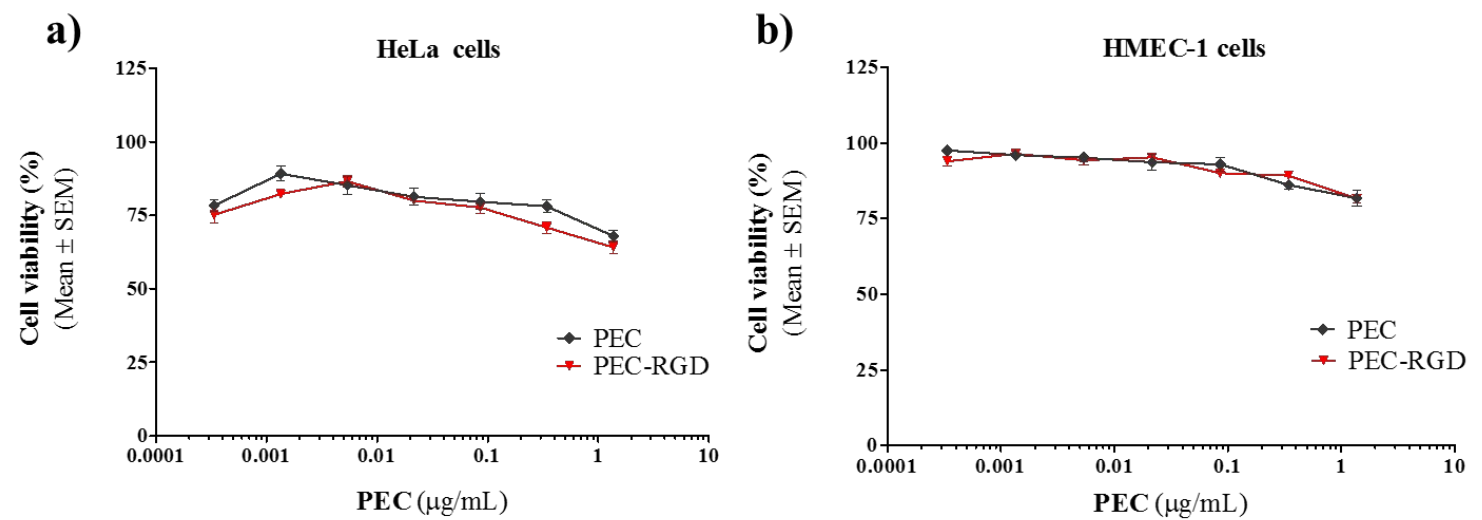

Figure 2. Effect of PEC and PEC-RGD on HeLa (a) and HMEC-1 (b) cell viability. The results presented correspond to the average of 3 independent experiments. 


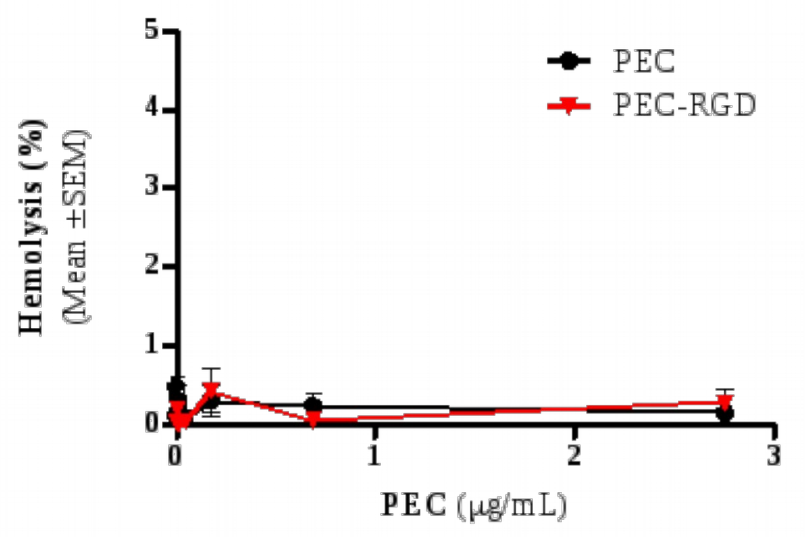

Figure 3. Effect of PEC and PEC-RGD on the hemolysis of mice RBC. The results presented correspond to the average of 3 independent experiments.

\subsection{Cell internalization}

We have demonstrated in a previous work that the GLA loaded PEC are easily taken up by endothelial cells and localized in the lysosomal compartments, when incubated in vitro for 2 h. ${ }^{5}$ In the present work, we aimed at comparing the uptake efficiency of PEC and PEC-RGD by endothelial cells, as they represent the target of choice for therapeutical intervention. HMEC-1 cells were incubated with fluorescently labeled PECs, PEC-Atto and PEC-Atto-RGD, for short periods of time, i.e. 10 and $20 \mathrm{~min}$, and PECs internalization was evaluated by flow cytometry. As shown in Figure 4a, $15.7 \pm$ $0.5 \%$ and $26.3 \pm 2.3 \%$ of the cells showed enhanced fluorescence when incubated with PEC-Atto for 10 and 20 min, respectively, while incubation with PEC-Atto-RGD for 10 and $20 \mathrm{~min}$ led to $24.4 \pm 1.8 \%$ and $37.0 \pm 1.8 \%$ of positive cells, respectively. Interestingly, the percentage of positive cells and mean fluorescence intensity (MFI), both indicative of the amount of nanoparticles internalized by cells, were higher on cultures incubated with the PEC-Atto-RGD as compared to those treated with PEC-Atto. 
Such differences were increased for short times (10 min, $p=0.0129$, Figure 4), indicating that, as expected, receptor mediated internalization through the RGD binding of $\alpha_{v} \beta_{3}$ integrins is faster and more efficient than the non-targeted endocytic process.

a)

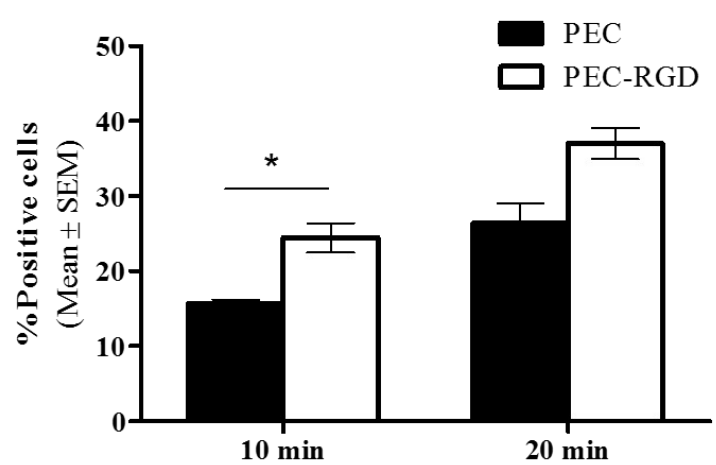

b)

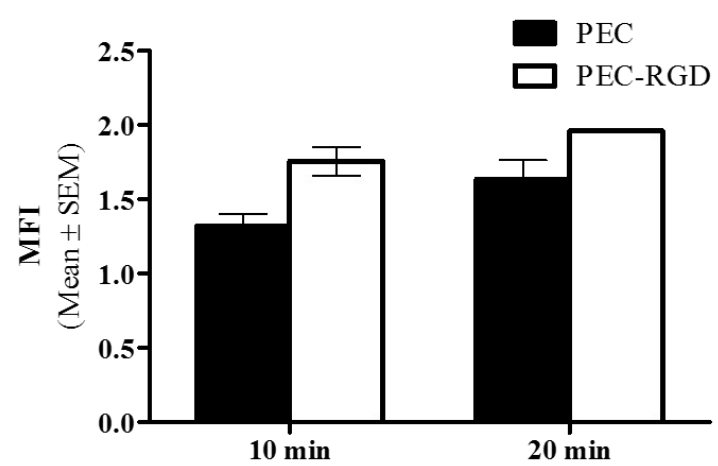

Figure 4. Uptake of Atto 647N-labeled PEC and PEC-RGD (PEC-Atto and PEC-AttoRGD) in live HMEC-1. a) Flow cytometry quantitation of the fraction of cells that had internalized PEC as the percentage of Atto $647 \mathrm{~N}$-positive cells among a given number of cells counted and b) mean fluorescence intensity (MFI) of Atto $647 \mathrm{~N}$ in the cells normalized to the maximum fluorescence intensity.

\subsection{Activity in primary cultures: Gb3 loss in endothelial primary cultures of Fabry} mice

Since GLA activity reduces Gb3 deposits within the lysosomes, the efficacy of different PECs to diminish the intracellular Gb3 deposits was assessed in cell cultures and compared to the activity of free GLA. The percentage of Gb3 loss of primary cultures of mouse aortic endothelial cells (MAEC) of GLA deficient mice was evaluated after simultaneous incubation with fluorescently labeled Gb3 (NBD-Gb3) and GLA, PEC or PEC-RGD in different concentrations. Degradation of NBD-Gb3 by GLA 
occurs exclusively inside the late endosomes/lysosomes, where the $\mathrm{pH}$ conditions are the most favorable for the enzyme activity.

In order to refer the intracellular activity to the specific activity of GLA in the different samples, the enzymatic activity of free GLA, PEC and PEC-RGD was first assessed following the degradation of 4-MUG fluorometrically, in the conditions described in the Experimental section (section 2.10). The specific activity of the GLA is in some extent altered by the encapsulation process, as detailed in Table 4. A decrease in activity after encapsulation has previously been observed for GLA loaded TMC-based $\mathrm{PEC}^{5}$ and it is probably related to the more difficult accessibility to the substrate. Dissociation of the PECs and accessibility of the enzyme to the substrate is expected to be easier in the lysosome, with presence of many degrading enzymes, than in the test tube.

Figure 5 displays the Gb3 loss, obtained from the reduction in fluorescence due to the degradation of NBD-Gb3, plotted against the concentration of activity of GLA of the free GLA, PEC or PEG-RGD suspensions. The GLA concentration is represented in activity units $\left(\mathrm{U} \mathrm{mL}^{-1}\right)$ due to the variations in specific activity for the different samples tested. The curves show higher efficacy for both PEC and PEC-RGD when compared to free GLA, as there is a $50 \%$ loss of Gb3 (IC50) already at $7.6 \pm 0.9$ and $5.5 \pm 1.5 \mathrm{mU}$ $\mathrm{mL}^{-1}$ activity for PEC and PEC-RGD, respectively, while for the free GLA this occurs at an activity of $50.3 \pm 8.1 \mathrm{mU} \mathrm{mL}^{-1}$. These results suggest that GLA is better internalized by MAEC when loaded in the PECs, increasing significantly the efficacy (IC50 values for the $\mathrm{Gb} 3$ loss is $7.6 \pm 0.9 \mathrm{mU} \mathrm{mL}^{-1}$ for PEC while naked GLA requires $50.3 \pm 8.1 \mathrm{mU}$ 
$\mathrm{mL}^{-1}$ ). In addition, the slight decrease in IC50 for the RGD decorated PEC (IC50 values of $5.5 \pm 1.5 \mathrm{mU} \mathrm{mL}^{-1}$ ) may be associated with the higher internalization degree observed already in HMEC-1 when compared to the bare PECs.

Table 4. Specific enzymatic activity PEC, PEC-RGD and free GLA suspension tested in vitro

\begin{tabular}{|c|c|c|c|}
\hline & \multirow{2}{*}{$\begin{array}{l}\text { Protein } \\
\text { concentration } \\
\left(\mu \mathrm{g} \mathrm{mL} \mathbf{L}^{-1}\right)\end{array}$} & \multicolumn{2}{|c|}{ Activity (Mean \pm SD) } \\
\hline & & $\left(\mu \mathrm{mol} \mathrm{h} \mathbf{h}^{-1} \mathbf{m g}^{-1}\right)$ & $\left(\mathbf{U} \mathbf{m L}^{-1}\right)$ \\
\hline GLA & 373 & $1533.5 \pm 177.1$ & $9.533 \pm 1.101$ \\
\hline PEC & 16 & $487.9 \pm 39.8$ & $0.130 \pm 0.011$ \\
\hline PEC-RGD & 17 & $406.3 \pm 26.8$ & $0.115 \pm 0.008$ \\
\hline
\end{tabular}

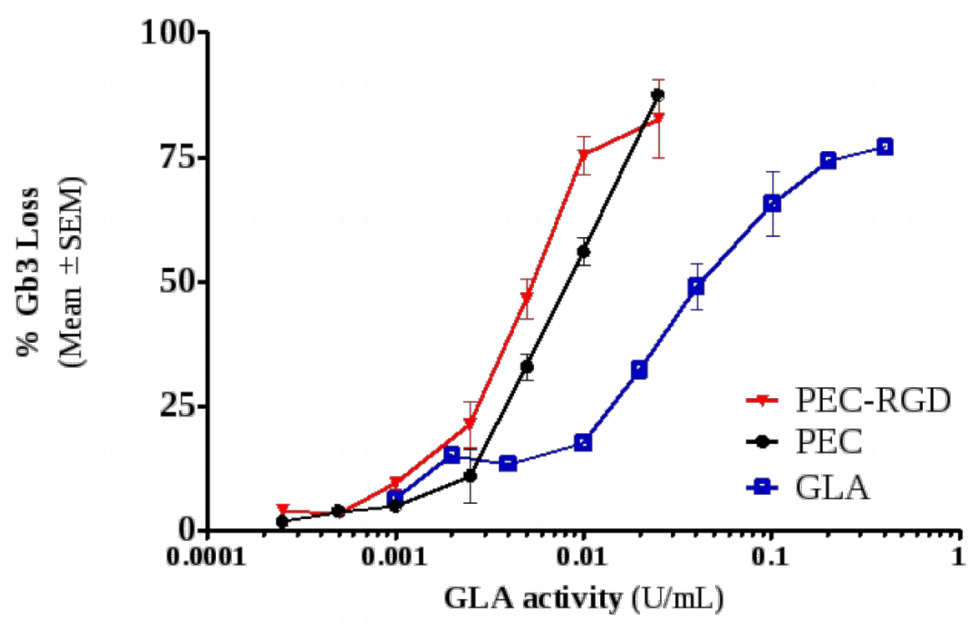

Figure 5. Activity of PEC, PEG-RGD and free GLA in primary cultures (MAEC KO cells). The mean percentage of Gb3 loss of three independent experiments is plotted $v s$. GLA activity concentration. 
The enzymatic activity of the freeze-dried PEC was tested immediately after resuspension in MilliQ water, and compared with the specific activity of the stock PEC suspension. Results in Table 5 show that the freeze-drying process not only does not affect the enzymatic activity of the encapsulated GLA, but also helps to preserve its activity, since all FD-PECs show higher enzymatic activity than the fresh PECs tested after 4 days of preparation. Besides, the presence of mannitol in the freeze-drying medium does not have a direct effect on the enzymatic activity in the test tube. Finally, although all freeze-dried PECs display good enzymatic activity after resuspension, the maximum activity is obtained after the freeze drying cycle 2 (FD2).

Table 5. Enzymatic activity GLA containing freeze-dried PECs and stock PEC and GLA suspensions. All tests were performed within the first days after PECs synthesis and immediately after resuspension, in the case of freeze-dried PECs.

\begin{tabular}{|c|c|c|c|}
\hline & \multirow{2}{*}{$\begin{array}{l}\text { Protein } \\
\text { concentration } \\
\left(\mu \mathrm{g} \mathrm{mL} \mathbf{~ L ~}^{-1}\right)\end{array}$} & \multicolumn{2}{|c|}{ Activity (Mean \pm SD) } \\
\hline & & $\left(\mu \mathrm{mol} \mathrm{h}{ }^{-1} \mathrm{mg}^{-1}\right)$ & $\left(\mathbf{U} \mathbf{m L}^{-1}\right)$ \\
\hline GLA & 1452 & $1681 \pm 165$ & $40.69 \pm 4.00$ \\
\hline PEC & 23 & $333.4 \pm 6.7$ & $0.106 \pm 0.003$ \\
\hline PEC-FD1 & 23 & $586.2 \pm 12.5$ & $0.191 \pm 0.005$ \\
\hline PEC-FD1-M & 23 & $606.2 \pm 33.5$ & $0.203 \pm 0.013$ \\
\hline PEC-FD2 & 23 & $808.3 \pm 65.6$ & $0.310 \pm 0.025$ \\
\hline PEC-FD2-M & 23 & $783.0 \pm 106$ & $0.300 \pm 0.041$ \\
\hline PEC-FD3 & 23 & $549.6 \pm 21.6$ & $0.211 \pm 0.008$ \\
\hline PEC-FD3-M & 23 & $582.9 \pm 30.0$ & $0.223 \pm 0.012$ \\
\hline
\end{tabular}


Accordingly, the intracellular activity of the PEC-FD2 was assessed and compared with that of the freshly prepared PECs. Figure 6 displays the Gb3 loss plotted against the concentration of activity of GLA for PEC, PEC-FD2 and PEC-FD2-M suspensions. Both PEC-FD2 and PEC-FD2-M display higher efficacy than PEC, with a $50 \%$ loss of Gb3 (IC50) at $1.5 \pm 0.2$ and $1.3 \pm 0.2 \mathrm{mU} \mathrm{mL}^{-1}$ activity for PEC-FD2 and PEC-FD2-M, respectively, and at $5.9 \pm 0.5 \mathrm{mU} \mathrm{mL}^{-1}$ for PEC, probably due to the stabilization of the PEC complex after freeze-drying procedure.

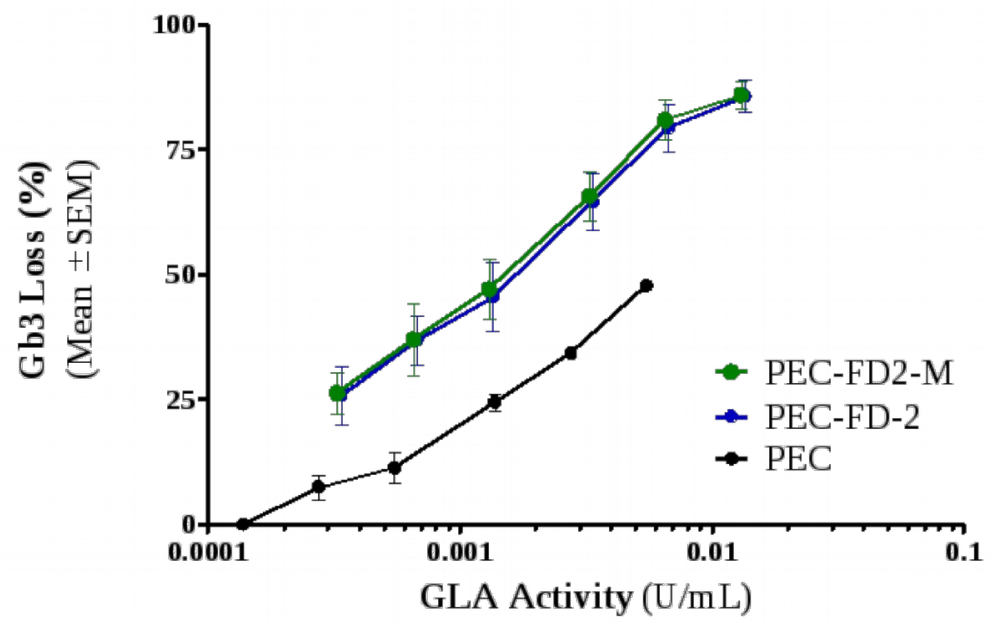

Figure 6. In vitro activity of GLA containing freeze-dried PECs in primary cultures (MAEC KO cells): Gb3 loss vs. GLA activity after incubation with resuspended PECFD2 and PEC-FD2-M, or freshly prepared PEC.

\section{DISCUSSION}

Pharmacological treatment of LSDs is in most cases based on the ERT with purified recombinant enzymes. The lysosomal destiny of infused enzymes by ERT relies in the 
presence of M6P at the protein and its ability to interact with the cell membrane via M6P receptors. Enzyme loaded in nanoparticle-based nanocarriers is a promising alternative to increase the efficacy of ERT treatment as they can provide a versatile platform to tackle several issues dealing with intracellular delivery of therapeutic macromolecules. Encapsulation within nanocarries can influence blood circulation times and protect biomacromolecules from protease degradation and immune system reaction. Furthermore, they allow tailoring the interaction with the cell membrane and release of the cargo by tuning the nanoparticle physicochemical properties, functionalization with specific ligands, etc, in order to tackle specific tissues, organs, cell types, and even organelles.

Here, we have developed a PEC based on the ionic interaction between the lysosomal enzyme GLA, deficient in the LSD called Fabry disease, and TMC, using TPP as ionic crosslinker..$^{5}$ The ionic nature of the PECs has the advantage of simple preparation procedures, due to the self-assembling nature of the system, which is of great importance when the cargo is a biomacromolecule, sensitive to harsh synthesis conditions like high temperatures, solvents or extreme $\mathrm{pH}^{43}$ In addition, it permits tailoring of the nanoparticle properties by modifying only one of the PECs components, the TMC in this case. Using this strategy, we have developed PECs capable to selfassemble at neutral $\mathrm{pH}$ by simply mixing components and stirring, and disassemble at endo-lysosomal acidic $\mathrm{pH}$, where the GLA is most active. The PECs have average $D$ between 170 and $250 \mathrm{~nm}$ and very low PDI (0.1-0.2) measured by DLS, and positive $\xi$ potential in the range of $16-19 \mathrm{mV}$ at $\mathrm{pH} 7.4$ (Table 2), suggesting that the nanoparticles 
surface expose mainly TMC than GLA, as the protein is negatively charged at neutral $\mathrm{pH}^{44}$

It has been proposed that the strong interaction of cationic nanoparticles with the negatively charged cell membrane may cause membrane disruption, leading to cell death, ${ }^{41}$ but it is also evidence that the toxicity of cationic nanoparticles depends on cellspecific uptake mechanisms and pathways. ${ }^{45}$ Following safety concerns for future in vivo applications, we investigated the potential toxicity of the PECs on HeLa, a routinely used cell line for cytotoxicity evaluation, and HMEC-1 cells, as vascular endothelial cells represent the main target for therapeutics in Fabry disease. ${ }^{19-21}$ For PEC concentrations up to $5.5 \mu \mathrm{g} \mathrm{mL} \mathrm{m}^{-1}$ cell viability is not significantly affected, maintained around $80 \%$ (Figure 2). Besides, hemolysis of the PECs suspensions was always lower than $1 \%$ when tested against mouse RBC (Figure 3), clearly below the 5\% value considered as the toxicity threshold. These results are in agreement with other reports on TMC based nanovectors with low toxicity ${ }^{46}$ and also show a correlation of the cytotoxicity with other structural parameters besides surface charge, like size of the nanoparticles, molecular weight of chitosan and acetylation degree. ${ }^{47}$ Moreover, the lowered buffering capacity of chitosan after methylation ${ }^{5}$ prevents endo-lysosomal disruption and scape ${ }^{48}$ which in combination with the dissociation capacity of the PECs at low $\mathrm{pH}^{5}$ and the eventual TMC degradation by lysosomal enzymes, may preserve lysosomal function after PECs internalization.

In previous studies we demonstrated that the PECs were efficiently internalized by HMEC-1 cells in vitro, after $2 \mathrm{~h}$ incubation, with endosomal/lysosomal destination 
confirmed by multicolor fluorescence microscopy. ${ }^{5}$ This nonspecific cell uptake most likely takes place by adsorptive endocytosis. ${ }^{49,50}$ Here, we explored the introduction of peptides ligands that include the RGD motif in the PECs structure, to target integrins like $\alpha_{v} \beta_{3}$, expressed in endothelial cells and upregulated during inflammation or angiogenesis and also in Fabry patients. ${ }^{22-27,51}$ Conjugation of $\mathrm{c}$ (RGDfk) to TMC is a simple procedure, and allows obtaining RGD-conjugated-PECs (PEC-RGD), without significant alterations of the particle average diameter and a slight decrease in $\xi$ potential value (Table 2), probably due to the exposure of RGD peptide on the surface. The PEC-RGD showed the same cell viability, when evaluated on HeLa and HMEC-1 cell lines (Figure 2), and hemocompatibility (Figure 3) of the PECs. Still, versatility of the PECs may allow introducing other types of ligands to target for example ICAM- $1 .{ }^{52}$, 53

Using a similar strategy, by conjugation of TMC with a fluorescent moiety (Atto 647N), fluorescent PEC and PEC-RGD were prepared to follow cell uptake by FACS, also maintaining average $D$ and with a minor decrease in $\xi$-potential (Table 1). When comparing the internalization of PEC and PEC-RGD by HMEC-1 after incubation for short times, i.e. 10 and $20 \mathrm{~min}$, an increase in the number of positive cells was observed for both PEC and PEC-RGD over time (Figure 4). However, statistically significant difference in the amount of positive cells between PEC and PEC-RGD uptake was mainly observed at 10 min incubation time. It is important to take into account that, due to the preparation method, it is not possible to control the location and orientation of the RGD motif within the PEC. The addition of TMC and TMC-RGD solutions to the GLA 
+ TPP solution is done in subsequent steps, in order for the first complexes to be formed with the TMC, and then complete the particle formation with the TMC-RGD. We expect that the amount of RGD be higher on the outer layers of the PEC than on the core; however, we have no evidence to support this hypothesis. Still, even when HMEC-1 internalization occurs fast and in great extent for both PEC and PEC-RGD, the enhanced uptake of RGD decorated PEC at short incubation times is evidenced (Figure 4), suggesting a quick and efficient receptor-mediated uptake, or at least a combination of both nonspecific and receptor-mediated endocytosis.

Preservation of enzymatic activity of GLA after encapsulation in the PECs is essential. A first, test following the degradation of 4-MUG fluorometrically revealed that GLA in PECs is active, but shows a decrease in activity after encapsulation (Table 4). This might be related to a hampered accessibility of the substrate because of a partial association of the enzyme and TMC persisting at acidic $\mathrm{pH}$. However, it is expected that in the lysosomal environment, pH-triggered release will be accompanied by the lysosomal enzymes degradation of TMC, ${ }^{54}$ facilitating enzyme-substrate interactions. In order to have more representative results of PECs efficacy in vitro, the evaluation of the degradation of NBD-Gb3 in primary GLA deficient cultures (Fabry mice) was assessed. As shown, results were promising, as both PEC and PEC-RGD display higher activity in MAEC KO cells than free GLA (Figure 5) with significantly lower IC50 (50.3 mU mL ${ }^{-1}$ for GLA and 7.6 and $5.5 \mathrm{mU} \mathrm{mL}^{-1}$ for PEC and PEC-RGD, respectively). This means that an important increase in intracellular activity is happening when GLA is encapsulated in PECs respect to the free GLA, even when certain loss of specific 
activity of GLA after encapsulation is happening. Consequently, less activity units of GLA are necessary to degrade Gb3 when the enzyme is encapsulated. It has been recently reported the increase of GLA activity when associated to liposomes, ${ }^{11}$ which has been related to the immobilization of the enzyme onto the lipid bilayer. A similar effect may be happening when GLA is interacting with TMC after PECs are dissociated inside the endo/lysosomal compartments, and partial association with TMC may still take place. Moreover, an increased efficiency due to the RGD ligand is detected, probably due to a higher internalization degree, or even to a more favorable uptake mechanism. It is well documented that nonspecific cell uptake of nanocarriers occurs mainly by endocytic process, ${ }^{55}$ and integrin-mediated internalization occurs when the carrier interacts with the cell surface receptors and are taken up into the target cells via receptor-mediated endocytosis. In both cases, the resulting endocytic vesicles fuse to form early endosomes and then mature into late endosomes which ultimately become part of the lysosomes. ${ }^{22}$ The occurrence of the uptake via the two different mechanisms is here suggested by the faster internalization observed in vitro for PEC-RGD than for PEC. This opens the possibility of an alternative glycosylation independent targeting ${ }^{53,56}$ for ERT, and might facilitate the use of non-glycosylated or partially glycosylated enzymes for treatment of LSD via ERT. Thus, GLA encapsulation will also endure a protection effect against GLA opsonization in the blood stream as previously demonstrated for other systems. ${ }^{57,58}$ Increased cellular levels of GLA or its activity in plasma have recently been reported on systems where GLA is also stabilized by other means, such as crosslinking and PEGylation, giving a prolonged circulatory half-life, ${ }^{57}$ 
or by the use of chaperones like Migalastat $\mathrm{HCl}^{58}$ Moreover, the increased advantage in the intracellular efficacy of the GLA when associated to the TMC in the PECs, particularly when decorated with RGD targeting moieties, would likely be evidenced when testing them in in vivo Fabry murine experimental models.

Finally, we have demonstrated that the PECs can be freeze-dried (FD) under controlled conditions to be preserved and administrated thereafter. We explored several FD cycles and the introduction of mannitol (PEC-FD-M), commonly used as a cryoprotector but also to achieve isosmotic solutions, to see its effect on the structure and properties of PEC-FD. Evaluating the physicochemical properties of the PECs after resuspension and the GLA enzymatic activity after the whole cycle allowed determining the optimal FD conditions (FD2), i.e. fasting freezing at $-40^{\circ} \mathrm{C}$. Using this cycle, the size and $\xi$-potential of the PECs after resuspension was not altered (Table 3) and the specific enzymatic activity of the GLA was preserved (Table 5), for both PECs with and without mannitol. The presence of mannitol did not introduce any change in physicochemical of the PECs or the biochemical properties of the loaded GLA. PECFD2 (as well as PEC-FD2-M) showed higher specific enzymatic activity than fresh PECs, probably due to the fact that the tests were performed 4 days after preparation, and while fresh PECs could lose part of the GLA structure and activity, FD-PEC preserved it. ${ }^{59}$ Not only was a higher specific enzymatic activity observed for PEC-FD but also a significant increase in NBD-Gb3 loss when tested on MAEC KO cells in vitro, with IC50 values of $5.9 \mathrm{mU} \mathrm{mL}^{-1}$ for PEC and 1.5 and $1.3 \mathrm{mU} \mathrm{mL}^{-1}$ for PEC-FD2 and PEC-FD2-M, respectively (Figure 6). Subsequently, when comparing PEC-FD2 
with the free GLA in suspension, the increase in efficacy is very high, with IC50 values from 50.3 to $1.5 \mathrm{mU} \mathrm{mL}^{-1}$. The FD process is a crucial step to preserve the PECs stable and active, and it could also serve as a way to slightly concentrate the sample when needed.

\section{CONCLUSIONS}

We have developed a versatile protein lysosomal delivery PEC based on the negatively charged lysosomal enzyme GLA, deficient in the LSD Fabry disease, and TMC, ionically crosslinked with TPP. Given its simple preparation strategy, it allows functionalization via conjugation of TMC with different moieties, like fluorophores and ligands, and also changing the cargo protein to tackle other LSDs. We evaluated the intracellular activity of the GLA loaded PECs, and the possibility of enhancing their efficacy as lysosomal delivery vectors in endothelial cells by introducing the RGD motif in the nanocarriers (PEC-RGD). We successfully prepared PEC and PEC-RGD with good physicochemical properties, low cytotoxicity and good hemocompatibility. PECs were efficiently taken up by endothelial cells in vitro, and the internalization was significantly higher for PEC-RGD than for PECs at short incubation times. Even more, we demonstrated an enhanced efficacy of PEC and PEC-RGD as compared to free GLA when evaluating the intracellular activity in primary cultures of GLA deficient mice. Relevantly, we optimized a FD protocol that allowed maintaining the physicochemical properties of the PECs while improving the biochemical ones, preserving the specific enzymatic activity of GLA and enhancing the efficacy in vitro in MAEC KO cells. The FD process is essential to preserve the PECs stable and active, and also could serve as a 
way to concentrate the sample when needed. Overall, the greater in vitro efficacy of PECs on primary cultures together with the enhanced specificity via the introduction of RGD ligands to enable more of the GLA reaching the endothelial cells, indicate the potential of PECs to enhance its efficacy in ERT in vivo and to reduce the amount of GLA and the frequency of administration required in current ERT of Fabry patients.

\section{AUTHOR INFORMATION}

\section{Corresponding Author}

*MIG: migiannotti@ub.edu; IA: ibane.abasolo@vhir.org

\section{Present Addresses}

^Institut de Ciència de Materials de Barcelona (ICMAB-CSIC), Campus Universitari de Bellaterra, 08193 Cerdanyola del Vallès, Spain, and Centro de Investigación Biomédica en Red -Bioingeniería, Biomateriales y Nanomedicina (CIBER-BBN), Spain.

\section{Author Contributions}

The manuscript was written through contributions of all authors. All authors have given approval to the final version of the manuscript. ${ }^{+}$These authors contributed equally.

\section{Notes}

The authors declare no competing financial interests.

\section{ACKNOWLEDGMENT}


We acknowledge financial support from Instituto de Salud Carlos III, through “Acciones CIBER". The Networking Research Center on Bioengineering, Biomaterials and Nanomedicine (CIBER-BBN) is an initiative funded by the VI National R\&D\&I Plan 2008-2011, Iniciativa Ingenio 2010, Consolider Program, CIBER Actions and financed by the Instituto de Salud Carlos III with assistance from the European Regional Development Fund. The authors appreciate the financial support through the "Development of nanomedicines for enzymatic replacement therapy in Fabry disease" project, granted by the Fundació Marató TV3, from the Catalan government (grant 2014SGR-1251) and Spanish Ministry of Economy and Competitiveness (MINECO) and FEDER projects (SAF2014-60138-R, CTQ2015-66194-R MINECO/FEDER). MINECO "Severo Ochoa" Programme for Centres of Excellence in R\&D (SEV-20150522) and Fundación Privada Cellex. AV is recipient of an ICREA Academia (Generalitat de Catalunya) award. We also acknowledge the ICTS "NANBIOSIS", more specifically the CIBER-BBN's In Vivo Experimental Platform at the Functional Validation \& Preclinical Research (FVPR) area (www.nanbiosis.es/unit/u20-in-vivoexperimental-platform) and the Protein Production Platform of CIBER-BBN/IBB, at the UAB SepBioES scientific-technical service (http://www.nanbiosis.es/unit/u1-proteinproduction-platform-ppp/).

\section{REFERENCES}

(1) Futerman, A. H.; van Meer, G., The cell biology of lysosomal storage disorders. Nat. Rev. Mol. Cell Biol. 2004, 5, 554-565. 
(2) Fabry Disease: Perspectives from 5 Years of FOS. Oxford PharmaGenesis: 2006.

(3) Kirkegaard, T., Emerging therapies and therapeutic concepts for lysosomal storage diseases. Expert Opin. Orph. Drug. 2013, 1, 385-404.

(4) Tang, R.; Kim, C. S.; Solfiell, D. J.; Rana, S.; Mout, R.; Velázquez-Delgado, E. M.; Chompoosor, A.; Jeong, Y.; Yan, B.; Zhu, Z.-J.; Kim, C.; Hardy, J. A.; Rotello, V. M., Direct Delivery of Functional Proteins and Enzymes to the Cytosol Using Nanoparticle-Stabilized Nanocapsules. ACS Nano 2013, 7, 6667-6673.

(5) Giannotti, M. I.; Esteban, O.; Oliva, M.; García-Parajo, M. F.; Sanz, F., pHresponsive polysaccharide-based polyelectrolyte complexes as nanocarriers for lysosomal delivery of therapeutic proteins. Biomacromolecules 2011, 12, 2524-2533.

(6) Lu, Y.; Sun, W.; Gu, Z., Stimuli-responsive nanomaterials for therapeutic protein delivery. J. Control. Release 2014, 194, 1-19.

(7) Fahmy, T. M.; Fong, P. M.; Goyal, A.; Saltzman, W. M., Targeted for drug delivery. Mater. Today 2005, 8, 18-26.

(8) Bae, Y. H.; Park, K., Targeted drug delivery to tumors: Myths, reality and possibility. J. Control. Release 2011, 153, 198-205.

(9) Rajendran, L.; Knolker, H.-J.; Simons, K., Subcellular targeting strategies for drug design and delivery. Nat. Rev. Drug. Discov. 2010, 9, 29-42. 
(10) Wexselblatt, E.; Esko, J. D.; Tor, Y., GNeosomes: Highly lysosomotropic nanoassemblies for lysosomal delivery. ACS Nano 2015, 9, 3961-3968.

(11) Cabrera, I.; Abasolo, I.; Corchero, J. L.; Elizondo, E.; Gil, P. R.; Moreno, E.; Faraudo, J.; Sala, S.; Bueno, D.; González-Mira, E.; Rivas, M.; Melgarejo, M.; Pulido, D.; Albericio, F.; Royo, M.; Villaverde, A.; García-Parajo, M. F.; Schwartz, S.; Ventosa, N.; Veciana, J., $\alpha$-Galactosidase A loaded nanoliposomes with enhanced enzymatic activity and intracellular penetration. Adv. Healthc. Mater. 2016, 5, 829-840.

(12) Maniganda, S.; Sankar, V.; Nair, J. B.; Raghu, K. G.; Maiti, K. K., A lysosometargeted drug delivery system based on sorbitol backbone towards efficient cancer therapy. Org. Biomol. Chem. 2014, 12, 6564-6569.

(13) Oh, N. M.; Oh, K. T.; Youn, Y. S.; Lee, D.-K.; Cha, K.-H.; Lee, D. H.; Lee, E. S., Poly(l-aspartic acid) nanogels for lysosome-selective antitumor drug delivery. Colloids Surf. B Biointerfaces 2013, 101, 298-306.

(14) Zhu, S.; Lansakara-P, D. S. P.; Li, X.; Cui, Z., Lysosomal delivery of a lipophilic gemcitabine prodrug using novel acid-sensitive micelles improved its antitumor activity. Bioconjugate Chem. 2012, 23, 966-980.

(15) Nair, J. B.; Mohapatra, S.; Ghosh, S.; Maiti, K. K., Novel lysosome targeted molecular transporter built on a guanidinium-poly-(propylene imine) hybrid dendron for efficient delivery of doxorubicin into cancer cells. Chem. Comm. 2015, 51, 2403-2406. 
(16) Meerovich, I.; Koshkaryev, A.; Thekkedath, R.; Torchilin, V. P., Screening and optimization of ligand conjugates for lysosomal targeting. Bioconjugate Chem. 2011, 22, $2271-2282$.

(17) Duncan, R.; Richardson, S. C. W., Endocytosis and intracellular trafficking as gateways for nanomedicine delivery: opportunities and challenges. Mol. Pharm. 2012, 9, $2380-2402$.

(18) Desnick, R. J.; Schuchman, E. H., Enzyme replacement and enhancement therapies: lessons from lysosomal disorders. Nat. Rev. Genet. 2002, 3, 954-966.

(19) Brady, R. O.; Gal, A. E.; Bradley, R. M.; Martensson, E.; Warshaw, A. L.; Laster, L., Enzymatic defect in Fabry's disease. N. Engl. J. Med. 1967, 276, 1163-1167.

(20) Kint, J. A., Fabry's Disease: Alpha-galactosidase deficiency. Science 1970, 167, 1268-1269.

(21) Aerts, J. M.; Groener, J. E.; Kuiper, S.; Donker-Koopman, W. E.; Strijland, A.; Ottenhoff, R.; van Roomen, C.; Mirzaian, M.; Wijburg, F. A.; Linthorst, G. E.; Vedder, A. C.; Rombach, S. M.; Cox-Brinkman, J.; Somerharju, P.; Boot, R. G.; Hollak, C. E.; Brady, R. O.; Poorthuis, B. J., Elevated globotriaosylsphingosine is a hallmark of Fabry disease. Proc. Natl. Acad. Sci. USA 2008, 105, 2812-2817. 
(22) Kowalski, P. S.; Leus, N. G. J.; Scherphof, G. L.; Ruiters, M. H. J.; Kamps, J. A.

A. M.; Molema, G., Targeted siRNA delivery to diseased microvascular endothelial cells

- Cellular and molecular concepts. IUBMB Life 2011, 63, 648-658.

(23) Muro, S.; Garnacho, C.; Champion, J. A.; Leferovich, J.; Gajewski, C.;

Schuchman, E. H.; Mitragotri, S.; Muzykantov, V. R., Control of endothelial targeting and intracellular delivery of therapeutic enzymes by modulating the size and shape of ICAM-1-targeted carriers. Mol. Ther. 2008, 16, 1450-1458.

(24) Chen, K.; Chen, X., Integrin Targeted Delivery of Chemotherapeutics. Theranostics 2011, 1, 189-200.

(25) Suh, W.; Han, S.-O.; Yu, L.; Kim, S. W., An angiogenic, endothelial-celltargeted polymeric gene carrier. Mol. Ther. 2002, 6, 664-672.

(26) Danhier, F.; Breton, A. L.; Préat, V., RGD-based strategies to target alpha(v) beta(3) integrin in cancer therapy and diagnosis. Mol. Pharm. 2012, 9, 2961-2973.

(27) Xiong, X.-B.; Mahmud, A.; Uludağ, H.; Lavasanifar, A., Conjugation of arginine-glycine-aspartic acid peptides to poly(ethylene oxide)-b-poly( $\varepsilon$-caprolactone) micelles for enhanced intracellular drug delivery to metastatic tumor cells. Biomacromolecules 2007, 8, 874-884. 
(28) Sieval, A. B.; Thanou, M.; Kotzé, A. F.; Verhoef, J. C.; Brussee, J.; Junginger, H. E., Preparation and NMR characterization of highly substituted N-trimethyl chitosan chloride. Carbohydr. Polym. 1998, 36, 157-165.

(29) Verheul, R. J.; Amidi, M.; van der Wal, S.; van Riet, E.; Jiskoot, W.; Hennink, W. E., Synthesis, characterization and in vitro biological properties of O-methyl free N,N,N-trimethylated chitosan. Biomaterials 2008, 29, 3642-3649.

(30) Rocas, P.; Fernandez, Y.; Schwartz, S., Jr.; Abasolo, I.; Rocas, J.; Albericio, F., Multifunctionalized polyurethane-polyurea nanoparticles: hydrophobically driven selfstratification at the o/w interface modulates encapsulation stability. J. Mat. Chem. B 2015, 3, 7604-7613.

(31) Dai, X.; Su, Z.; Liu, J. O., An improved synthesis of a selective $\alpha v \beta 3$-integrin antagonist cyclo(-RGDfK-). Tetrahedron Lett. 2000, 41, 6295-6298.

(32) Dziadek, S.; Jacques, S.; Bundle, D. R., A novel linker methodology for the synthesis of tailored conjugate vaccines composed of complex carbohydrate antigens and specific TH-cell peptide epitopes. Chem. Eur. J. 2008, 14, 5908-5917.

(33) Wiechelman, K. J.; Braun, R. D.; Fitzpatrick, J. D., Investigation of the bicinchoninic acid protein assay: Identification of the groups responsible for color formation. Anal. Biochem. 1988, 175, 231-237. 
(34) Corchero, J. L.; Mendoza, R.; Lorenzo, J.; Rodríguez-Sureda, V.; Domínguez, C.; Vázquez, E.; Ferrer-Miralles, N.; Villaverde, A., Integrated approach to produce a recombinant, his-tagged human $\alpha$-galactosidase a in mammalian cells. Biotechnol. Prog. 2011, 27, 1206-1217.

(35) Bomati-Miguel, O.; Miguel-Sancho, N.; Abasolo, I.; Candiota, A. P.; Roca, A. G.; Acosta, M.; Schwartz, S., Jr.; Arus, C.; Marquina, C.; Martinez, G.; Santamaria, J., Ex vivo assessment of polyol coated-iron oxide nanoparticles for MRI diagnosis applications: toxicological and MRI contrast enhancement effects. J. Nanopart. Res. 2014, 16 (2292), 1-13.

(36) Botella, P.; Abasolo, I.; Fernández, Y.; Muniesa, C.; Miranda, S.; Quesada, M.; Ruiz, J.; Schwartz Jr, S.; Corma, A., Surface-modified silica nanoparticles for tumortargeted delivery of camptothecin and its biological evaluation. J. Control. Release 2011, 156, 246-257.

(37) Desnick, R. J.; Allen, K. Y.; Desnick, S. J.; Raman, M. K.; Bernlohr, R. W.; Krivit, W., Fabrys disease - enzymatic diagnosis of hemizygotes and heterozygotes alpha-galactosidase activities in plasma, serum, urine, and leukocytes. J. Lab. Clin. Med. 1973, 81, 157-171.

(38) Mayes, J. S.; Scheerer, J. B.; Sifers, R. N.; Donaldson, M. L., Differential assay for lysosomal alpha-galactosidases in human tissues and its application to Fabry's disease. Clin. Chim. Acta 1981, 112, 247-251. 
(39) Shu, L.; Murphy, H. S.; Cooling, L.; Shayman, J. A., An in vitro model of Fabry disease. J. Am. Soc. Nephr. 2005, 16, 2636-2645.

(40) Ohshima, T.; Murray, G. J.; Swaim, W. D.; Longenecker, G.; Quirk, J. M.; Cardarelli, C. O.; Sugimoto, Y.; Pastan, I.; Gottesman, M. M.; Brady, R. O.; Kulkarni, A. B., $\alpha$-Galactosidase A deficient mice: A model of Fabry disease. Proc. Natl. Acad. Sci. USA 1997, 94, 2540-2544.

(41) Fröhlich, E., The role of surface charge in cellular uptake and cytotoxicity of medical nanoparticles. Int. J. Nanomed. 2012, 7, 5577-5591.

(42) Ades, E. W.; Candal, F. J.; Swerlick, R. A.; George, V. G.; Summers, S.; Bosse, D. C.; Lawley, T. J., HMEC-1: Establishment of an immortalized human microvascular endothelial cell line. J. Investig. Dermatol. 1992, 99, 683-690.

(43) Insua, I.; Wilkinson, A.; Fernandez-Trillo, F., Polyion complex (PIC) particles: Preparation and biomedical applications. Eur. Polym. J. 2016, 81, 198-215.

(44) Garman, S. C.; Garboczi, D. N., The molecular defect leading to Fabry disease:

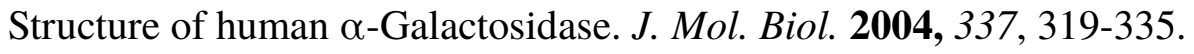

(45) Xia, T.; Kovochich, M.; Liong, M.; Zink, J. I.; Nel, A. E., Cationic polystyrene nanosphere toxicity depends on cell-specific endocytic and mitochondrial injury pathways. ACS Nano 2008, 2, 85-96. 
(46) Amidi, M.; Romeijn, S. G.; Borchard, G.; Junginger, H. E.; Hennink, W. E.; Jiskoot, W., Preparation and characterization of protein-loaded N-trimethyl chitosan nanoparticles as nasal delivery system. J. Control. Release 2006, 111, 107-116.

(47) Elgadir, M. A.; Uddin, M. S.; Ferdosh, S.; Adam, A.; Chowdhury, A. J. K.; Sarker, M. Z. I., Impact of chitosan composites and chitosan nanoparticle composites on various drug delivery systems: A review. J. Food Drug Anal. 2015, 23, 619-629.

(48) Nel, A. E.; Madler, L.; Velegol, D.; Xia, T.; Hoek, E. M. V.; Somasundaran, P.; Klaessig, F.; Castranova, V.; Thompson, M., Understanding biophysicochemical interactions at the nano-bio interface. Nat. Mater. 2009, 8, 543-557.

(49) Mourya, V. K.; Inamdar, N. N., Trimethyl chitosan and its applications in drug delivery. J. Mater. Sci.: Mater. Med. 2009, 20, 1057-1079.

(50) Raub, T. J.; Audus, K. L., Adsorptive endocytosis and membrane recycling by cultured primary bovine brain microvessel endothelial-cell monolayers. J. Cell Sci. 1990, 97, 127-138.

(51) Utsumi, K.; Itoh, K.; Kase, R.; Shimmoto, M.; Yamamoto, N.; Katagiri, Y.; Tanoue, K.; Kotani, M.; Ozawa, T.; Oguchi, T.; Sakuraba, H., Urinary excretion of the vitronectin receptor (integrin $\alpha \mathrm{V} \beta 3$ ) in patients with Fabry disease. Clin. Chim. Acta 1999, 279, 55-68. 
(52) Hsu, J.; Serrano, D.; Bhowmick, T.; Kumar, K.; Shen, Y.; Kuo, Y. C.; Garnacho, C.; Muro, S., Enhanced endothelial delivery and biochemical effects of [alpha]galactosidase by ICAM-1-targeted nanocarriers for Fabry disease. J. Control. Release 2011, 149, 323-331.

(53) Muro, S.; Schuchman, E. H.; Muzykantov, V. R., Lysosomal enzyme delivery by ICAM-1-targeted nanocarriers bypassing glycosylation- and clathrin-dependent endocytosis. Mol. Ther. 2006, 13, 135-141.

(54) Verheul, R. J.; Amidi, M.; van Steenbergen, M. J.; van Riet, E.; Jiskoot, W.; Hennink, W. E., Influence of the degree of acetylation on the enzymatic degradation and in vitro biological properties of trimethylated chitosans. Biomaterials 2009, 30, 31293135.

(55) Dehousse, V.; Garbacki, N.; Colige, A.; Evrard, B., Development of pHresponsive nanocarriers using trimethylchitosans and methacrylic acid copolymer for siRNA delivery. Biomaterials 2010, 31, 1839-1849.

(56) LeBowitz, J. H.; Grubb, J. H.; Maga, J. A.; Schmiel, D. H.; Vogler, C.; Sly, W. S., Glycosylation-independent targeting enhances enzyme delivery to lysosomes and decreases storage in mucopolysaccharidosis type VII mice. Proc. Natl. Acad. Sci. USA 2004, 101, 3083-3088.

(57) Kizhner, T.; Azulay, Y.; Hainrichson, M.; Tekoah, Y.; Arvatz, G.; Shulman, A.; Ruderfer, I.; Aviezer, D.; Shaaltiel, Y., Characterization of a chemically modified plant 
cell culture expressed human $\alpha$-Galactosidase-A enzyme for treatment of Fabry disease. Mol. Genet. Metab. 2015, 114, 259-267.

(58) Warnock, D. G.; Bichet, D. G.; Holida, M.; Goker-Alpan, O.; Nicholls, K.; Thomas, M.; Eyskens, F.; Shankar, S.; Adera, M.; Sitaraman, S.; Khanna, R.; Flanagan, J. J.; Wustman, B. A.; Barth, J.; Barlow, C.; Valenzano, K. J.; Lockhart, D. J.; Boudes, P.; Johnson, F. K., Oral migalastat $\mathrm{HCl}$ leads to greater systemic exposure and tissue levels of active $\alpha$-Galactosidase A in Fabry patients when co-administered with infused agalsidase. PLOS ONE 2015, 10, e0134341.

(59) Rodrigues, S.; Cordeiro, C.; Seijo, B.; Remuñán-López, C.; Grenha, A., Hybrid nanosystems based on natural polymers as protein carriers for respiratory delivery: Stability and toxicological evaluation. Carbohydr. Polym. 2015, 123, 369-380.

\section{TABLE OF CONTENTS GRAPHIC}

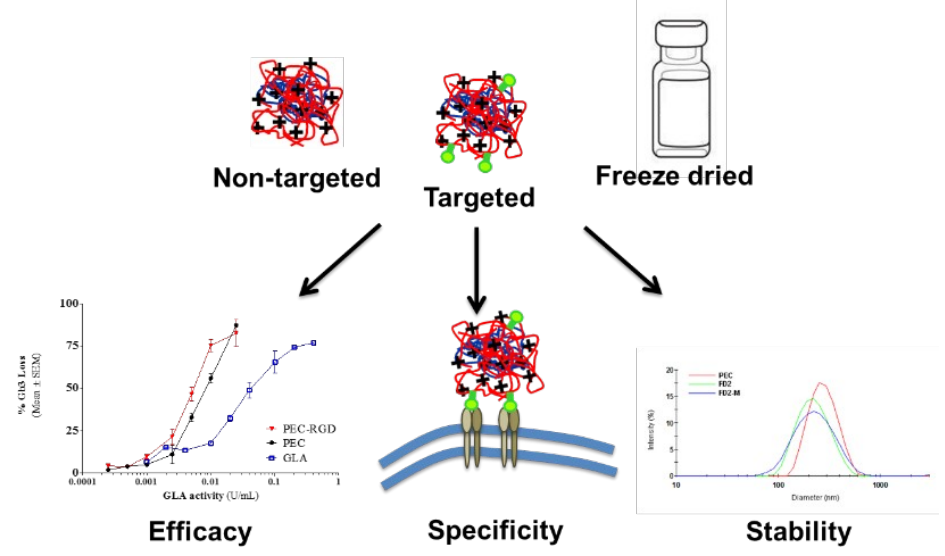


